\title{
Clinical diagnosis of ankylosing spondylitis in women and relation to presence of HLA-B27
}

\author{
HILARY F. H. HILL, ALAN G. S. HILL, AND JULIA G. BODMER \\ From the Oxford Regional Rheumatic Diseases Research Centre, Stoke Mandeville Hospital, and the Genetics \\ Laboratory, Department of Biochemistry, University of Oxford
}

\begin{abstract}
Hill, H. F. H., Hill, A. G. S., and Bodmer, J. G. (1976). Annals of the Rheumatic Diseases, 35, 267-270. Clinical diagnosis of ankylosing spondylitis in women and relation to presence of HLA-B27. Thirty-nine Caucasian women with definite or probable ankylosing spondylitis were tissue typed and the radiographic and clinical features were correlated with the presence of B27 (formerly W27). This investigation showed that the same strong positive correlation observed in men obtains in women between $B 27$ and unequivocal radiographic changes. As such changes develop slowly in women, clinical and laboratory features were identified which were sufficiently characteristic to enable the diagnosis to be reached in advance of decreased spinal mobility. Immobility pain and stiffness and bilateral sacroiliac pain are the most characteristic features, but additional support is provided by the presence of any of the following: onset by age 30, a raised sedimentation rate, peripheral joint involvement, circumthoracic pain, family history, and iritis.
\end{abstract}

Rheumatologists recognize that ankylosing spondylitis (AS) is not as uncommon in women as many physicians believe, although there is wide variation in the precise ratios quoted $(10: 1$ West, $1949 ; 8: 1$ Lawrence, 1963; 4 :1 Mason, 1964; 3·3 :1 Hill, 1964). West's ratio reflects referral for radiotherapy, Lawrence's a population survey, Mason's and Hill's unequivocal clinical and radiographic AS as seen in typical rheumatological clinics. When a presumptive diagnosis of AS is made in advance of definitive radiographic changes then the ratio is $2 \cdot 3: 1$ (H. F. H. Hill and A. G. S. Hill, unpublished data, 1975). The precise ratio is less important than the fact that AS does occur in women and should be included in the differential diagnosis of back pain. Even so it can be difficult to reach a definite diagnosis as the clinical and radiographic evolution is often slower than in men (Tyson, Thompson, and Ragan, 1953; Hart and Robinson, 1959). A strong positive association exists between the histocompatibility antigen HLA-B27 (formerly W27) and AS in men and predominantly male mixed samples, at least $88 \%$ of patients belonging to this tissue type (Brewerton and others, 1973; Schlosstein and others, 1973). If the same strong positive correlation exists in women then it should be possible to identify a group of clinical and laboratory features which together are sufficiently characteristic of AS to enable the diagnosis to be reached without resort to radiographs or tissue typing. Hence the purpose of this investigation was to tissue type a group of women in whom a diagnosis of definite or probable AS had been made and to correlate this with radiographic, clinical, and laboratory data.

\section{Patients and methods}

Forty-seven women in whom the diagnosis of AS was made at the initial visit were identified from the department's index. Women with associated psoriasis, colitis, or Behçet's disease were excluded. Informed written consent was followed by examination. As a result of this the diagnosis was amended in 8 patients, and these were excluded from further study. In the remaining 39 tissue typing was done according to the technique described by Bodmer and Bodmer (1974), radiographs were scored according to the New York criteria (Bennett and Wood, 1968), and the diagnosis was assessed as being 'definite' or 'probable' by one author (A.G.S.H.) who had access only to the case notes and who remained ignorant of the radiographic grade or tissue type. 
Results

INCIDENCE OF HLA-B 27

B27 was present in 27 patients $(69 \cdot 2 \%)$ compared to $5-7 \%$ expected in a normal population. This association reached a very high level of significance $\left(\chi^{2}=59 \cdot 72, \mathrm{P} \ll 0.1 \%\right)$.

\section{RADIOGRAPHIC CHANGES}

Radiographs were available in 30 patients. Table I shows the striking correlation between unequivocal radiographic bilateral sacroiliitis and $B 27$, present in all 18 patients. Numbers in the other groups are small, but nearly $50 \%$ had B27.

\section{CLINICAL FEATURES}

As there is no one clinical feature characteristic of AS the diagnosis is usually reached by summation of features from the history, clinical examination, and laboratory investigations. The incidence of 10 potentially characteristic features in 'definite' and 'probable' groups are given in Table II, but some merit amplification.

ESR was not always raised at the first visit, but exceeded $20 \mathrm{~mm} / \mathrm{h}$ at some time in more than $80 \%$ of patients (range 4-126). Similarly a minimum ESR of $<20 \mathrm{~mm} / \mathrm{h}$ was recorded at some time in $80 \%$ of patients (range 1-46). Hence serial readings are invaluable.

The term immobility stiffness or pain has been used to cover discomfort which starts while the patient is at rest, for example in bed or seated in a chair or car, and is relieved by exercise. This history can often only be elicited by careful questioning.

Sacroiliac pain and stiffness is characteristically felt in the buttocks and posterior thighs, rarely extending below the knee-though frequently described by the patient as 'pain in my leg' or 'sciatica'.

Iritis present in 9 was in each instance associated with B27.

Dorsolumbar and lumbar pain were present in all except for one teenager (and served as a reminder to consider AS in the differential diagnosis).

Table I Radiographic changes and frequency of HLA-B27

\begin{tabular}{|c|c|c|}
\hline$X$-ray grade & $n$ & $\begin{array}{l}H L A-B 27 \\
\text { present }\end{array}$ \\
\hline $\begin{array}{l}\text { Not taken } \\
0=\text { normal } \\
1=\text { suspicious changes } \\
2=\text { minimal abnormality } \\
3=\text { unequivocal but unilateral, } \\
\text { or markedly asymmetrical } \\
3 \text { = bilateral unequivocal }\end{array}$ & $\begin{array}{l}9 \\
4 \\
2 \\
2\end{array}$ & $\begin{array}{l}4 \\
2 \\
1 \\
1\end{array}$ \\
\hline
\end{tabular}

Table II Clinical features and frequency of $H L A-B 27$

\begin{tabular}{|c|c|c|}
\hline $\begin{array}{l}\text { Ankylosing spondylitis } \\
\text { in women }\end{array}$ & Definite & Probable \\
\hline HLA-B27 present & $20 / 23 \mathrm{AB}$ & $7 / 16 \mathrm{AC}$ \\
\hline Onset by age 30 & $17 / 23$ & $12 / 16$ \\
\hline $\mathrm{ESR}>20$ & $20 / 23$ & $13 / 16$ \\
\hline Immobility pain/stiffness & $20 / 23$ & $13 / 16$ \\
\hline Bilateral SI pain/stiffness & $17 / 23$ & $4 / 16$ \\
\hline$\downarrow$ spinal movements & $20 / 23$ & $8 / 16$ \\
\hline Peripheral joint involvement & $13 / 23$ & $11 / 16$ \\
\hline Knee synovitis & $8 / 23$ & $6 / 16$ \\
\hline Circumthoracic pain & $11 / 23$ & $6 / 16$ \\
\hline Family history & $9 / 23$ & $2 / 16$ \\
\hline Iritis & $7 / 23$ & $2 / 16$ \\
\hline
\end{tabular}

Present in at least 74\% $\square$; present in $>\frac{1}{3} \square$; present in $<\frac{1}{3}$ :

(A) The difference in frequency of B27 in patients with definite and probable AS combined compared with normal controls has $\chi^{2}=59 \cdot 72$, $\mathrm{P}\langle<<0.1 \%$ (B) The difference in frequency of B27 patients definite AS compared with controls has $\chi^{2}=115 \cdot 16, \mathrm{P}\langle<<0.1 \%$. (C) The difference in frequency of B27 between patients with probable AS and normal controls has $x^{2}=15 \cdot 19, \mathrm{P}\langle\langle<0.1 \%$. The difference in frequency of $\rightarrow$ $B 27$ between definite and probable patients was significant at the $1 \% \overrightarrow{0}$ level $\left(x^{2}=6 \cdot 3\right)$. The incidence of proven family history of AS was not significant between the definite and probable groups.

When the history, clinical features, and ESR ae considered together a pattern develops. Onset by the age of 30, an ESR exceeding $20 \mathrm{~mm} / \mathrm{h}$, and immobility stiffness were present in $74 \%$ of patients irrespective of whether the diagnosis was regarded as definite or probable. This triad is enough to suggest a diagnosis of AS, but other features are needed before the diagnosis can be made with confidence.

Many of these features, particularly bilateral sacroiliitis, only develop with the passage of time as the evolution of the disease is slow. In this study the mean time for diagnosis was 9.97 years (range 9 months -37 years). This delay was reflected in the multiplicity of referrals to different hospital departments before the diagnosis was established, totaling 91 in 30 patients (range 1-7 separate referrals).

The association of $\mathrm{B} 27$ with both definite and probable clinical groups reached a very high level of $N$ significance $\left(\chi^{2}=115 \cdot 16, P \ll 0.1 \%\right.$ in the definite $N$ group; $\chi^{2}=15 \cdot 19, \mathrm{P} \ll 0 \cdot 1 \%$ in the probable group). The difference between the groups being significant at the $1 \% \operatorname{level}\left(\chi^{2}=6 \cdot 3\right)$.

\section{Discussion}

When Brewerton and Schlosstein (Brewerton and others, 1973; Schlosstein and others, 1973) first described the close association between B27 and AS no effort was spared to ensure that the diagnosis of $\varnothing$ AS was beyond doubt. As AS occurs more often in 
men than in women and as radiographic changes are more extensive and develop earlier in men, it was natural that their combined series of 115 patients contained only 3 women. However, as AS is difficult to diagnose in women, tissue typing could be a valuable aid to diagnosis if the same strong positive correlation exists between B27 and AS. Hence the first step in this study was to identify a group of women who fulfilled identical criteria to those used by Brewerton and Schlosstein. A group of 18 patients with bilateral unequivocal radiographic sacroiliitis fulfilled this requirement, and all 18 had B27. Therefore the same strong positive correlation exists in Caucasian women as in men. It was perhaps fortuitous that all 18 had B27 and it seems best to postulate that the association will exist in about $90 \%$ of patients.

The second step was to analyse the clinical features with which these 18 women with definite AS presented, adding to the group 5 more women in whom the clinical features were so characteristic that the diagnosis was beyond reasonable doubt, but in whom shorter disease duration accounted for the lack of definitive radiographic change. In this group of 23 patients B27 was present in $20(87 \%$ )-a figure in close agreement with those of Brewerton and Schlosstein. The association between B27 and AS is not absolute, and reasons for this have been discussed in detail by McDevitt and Bodmer (1974).

The third step was to analyse the clinical features in the 16 women in whom a probable diagnosis of AS had been made, 7 of these having B27 (44\%). Comparison was then made of the clinical features occurring in the definite and probable groups. The incidence of individual clinical features in the two groups are remarkably similar with three notable exceptions. Bilateral sacroiliac pain and stiffness was present in $1 / 4$ of the 'probables' but in $3 / 4$ of the 'definites': this may merely mean that many probables were seen early in the disease and that bilateral pain had not had time to develop, or may indicate that the diagnosis was not AS. Two of the 4 patients with bilateral sacroiliac pain in the probable group had B27. The second discordant clinical feature was decrease in spinal movements, present in $3 / 4$ of the 'definites' and $1 / 2$ of the 'probables'. This reflects shorter duration in the probable group. Finally, a definite family history of AS weighed heavily with the clinical assessor when allocating patients on the basis of history and clinical features alone to the probable or definite group. A definite family history of AS was present in $1 / 3$ of the 'definites' and $1 / 8$ of the 'probables', all but one of these 11 patients having B27. The most characteristic feature present in threequarters of the women in both definite and probable groups was immobility stiffness, a feature elicited only by asking the right questions and interpreting the reply correctly. There are other and usually commoner causes for the supporting features of AS, such as raised ESR, knee synovitis, involvement of other peripheral (usually large) joints, and circumthoracic pain, hence these cannot be classed as diagnostic features. Onset before the age of 30 is only an alerting feature. However, iritis, present in a smaller proportion of patients, carries more diagnostic weight, and all our women with iritis had B27.

This study confirms that the evolution of AS in women is slow with regard to both clinical and radiographic features, and this undoubtedly contributed to the delay in diagnosis of nearly 10 years which compares, unfavourably, to just under 3 years in men (Hart and others, 1949). This delay in diagnosis also suggests that in some women the diagnosis is never made, or is made only when symptoms have been replaced by ankylosis shown by a fortuitous radiograph taken for another purpose. Yet it is during the early years when pain and stiffness are prominent that patients need a firm (even if presumptive) diagnosis so that adequate treatment can be prescribed. Some women with ankylosing spondylitis present with classical features, but this is the exception rather than the rule. In the majority clinical and radiographic abnormalities are minimal, and in these patients a careful history is all-important. If this provides clear evidence of immobility pain and stiffness and bilateral sacroiliac pain, then it is not only justifiable, but good medicine to make a firm diagnosis and start treatment. The problem is greatest where the only complaint is of intermittent immobility stiffness and of unilateral sacroiliac pain, and in these patients any supporting feature, reviewed at successive visits can strengthen the tentative diagnosis.

The ESR if raised is helpful, but if normal does not exclude AS as normal levels were recorded in over $80 \%$ of our patients at some time in their illness. Tissue typing is rarely justified when the diagnosis can be confidently made on clinical grounds, but should be reserved for the women in which the diagnosis is in greatest doubt-if B27 is present then this immeasurably strengthens the presumptive diagnosis which should be named and treatment started. If B27 is not present then the diagnosis is very unlikely to be AS unless symptoms more characteristic of the disease appear with the passage of time. As resources for tissue typing are currently scarce, and as the association of B27 and AS is not absolute, tissue typing should for the time being at least be reserved for women in whom the diagnosis is in real doubt, but strongly suggestive of AS.

We thank Mrs. Danielle Young for the tissue typing. We are indebted to the Medical Research Council for support for J.G.B. and Mrs. Young; the Research Committee of the Oxford Regional Health Authority for support for H.F.H.H.; and the Arthritis and Rheumatism Council for providing a research secretary (Mrs. Janice Miles). 


\section{References}

BenNet, P. H., AND WoOD, P. H. N. (1968) 'Recommended criteria for use in population surveys' in 'Population Studies of the Rheumatic Diseases. Proceedings of the 3rd International Symposium', p. 456. International Congress Series, No. 148. Excerpta Medica, Amsterdam

BODmer, W. E., AND BODMer, J. G. (1974) 'Cytofluorochromasia' in 'Manual of Tissue Typing Techniques', p. 29. Publication No. (NIH) 74-545. Department of Health, Education, and Welfare, Bethesda, Maryland

Brewerton, D. A., Caffrey, M., Hart, F. D., James, D. C. O., Nicholls, A., AND Sturrock, R. D. (1973) Lancet, 1, 904 (Ankylosing spondylitis and HL-A27)

HART, F. D., AND RoBINSON, K. C. (1959) Ann. rheum. Dis., 18, 15 (Ankylosing spondylitis in women)

- , Allchin, F. M., AND MacLaGen, N. F. (1949) Quart. J. Med. 18, 217 (Ankylosing spondylitis)

Hill, A. G. S. (1964) 'Differential diagnosis' in 'Symposium Polyarthritis', No. 25, p. 25. R. C. P., Edinburgh

LAWRENCE, J. S. (1963) Brit. J. clin. Pract., 17, 699 (The prevalence of arthritis)

MCDeViT, H. O., AND BoDMER, W. E. (1974) Lancet, 1, 1269 (HL-A immune-response genes, and disease)

Mason, R. M. (1964) Proc. roy. Soc. Med., 57, 533 (Spondylitis)

Schlosstein, L., Terasaki, P. I., Bluestone, R., and Pearson, C. M. (1973) New. Engl. J. Med., 288, 704 (High association of an HL-A antigen, W27, with ankylosing spondylitis)

Tyson, T. L., Thompson, W. A. L., AND RAGAN, C. (1953) Ann. rheum. Dis., 12, 40 (Marie-Strümpell spondylitis in women)

WEST, H. F. (1949) Ibid., 8, 143 (The aetiology of ankylosing spondylitis) 